\title{
A IMPORTÂNCIA DA EQUIPE MULTIDISCIPLINAR NO ACOLHIMENTO A MULHER VÍTIMA DE VIOLÊNCIA SEXUAL
}

\author{
Camila M. Pitangui ${ }^{3}$, Iuri S. Luiz, Ogenira S. S. Klein ${ }^{3}$, Carolina M. Santos ${ }^{2}$ \& Roberta \\ Lastorina Rio ${ }^{1,2}$
}

\begin{abstract}
(1) Professora e Orientadora do curso de Enfermagem - Institutos Superiores de Ensino do CENSA - ISECENSA, Rua Salvador Correa, 139, Centro, Campos dos Goytacazes, RJ, Brasil; (2) Pesquisadora do Laboratório de Estudos em Saúde Pública (NUPENSP/ISECENSA); (3) Acadêmico (a) do curso de Enfermagem do ISECENSA.
\end{abstract}

A violência sexual é toda ação que obriga uma pessoa em estado de submissão por meio de intimidação, violência física, verbal e psicológica ao ato sexual. Com o aumento desta problemática, a violência sexual contra a mulher ganha maior visibilidade no âmbito da saúde pública, sendo assim reconhecida pela Organização Mundial de Saúde (OMS) e entidades ligadas aos diretos humanos como um fenômeno que agride todas as classes sociais, raças e religiões. Estima-se que, anualmente no Brasil, ocorra cerca de 527 mil casos de tentativas ou estupros consumados, dos quais somente $10 \%$ são relatados. São vários os motivos que levam a essa subnotificação, dentre os quais destaca-se a discriminação dos familiares, sociedade e autoridades. Nos casos de violência sexual, são apresentados não apenas problemas físicos, mas psicológicos, sociais e sexuais, tornando necessário que os hospitais de emergência, tenham um acolhimento humanizado, com uma visão holística e sem riscos de negligências, pelas equipes multidisciplinares. Faz-se necessário que os profissionais de saúde que atuam no enfrentamento à violência sejam capacitados a atender de modo harmônico, técnico e acolhedor, pois a interação gera melhor resolubilidade na assistência a mulher vítima de violência sexual. Neste contexto, o presente projeto tem como objetivo descrever a atuação dos profissionais de saúde da equipe multidisciplinar no acolhimento a mulher vítima de violência sexual. A pesquisa será de abordagem qualitativa, do tipo descritiva exploratória. Para tal, será aplicado um questionário contendo perguntas abertas e fechadas para 10 profissionais que atuam na equipe de emergência de um hospital público localizado no município de Campos dos Goytacazes- RJ. A análise de dados será realizada pela técnica de Bardin. Espera-se com esta pesquisa, enfatizar os conhecimentos dos profissionais da equipe multidisciplinar sobre as características da violência sexual contra a mulher, as condutas e os meios de comunicação utilizados no acolhimento assistencial, contribuindo assim para a qualificação na abordagem com atendimento íntegro e absoluto, fazendo-se entender a importância do serviço de atendimento, e as necessidades das mulheres vítimas de violência sexual.

Palavras-chave: equipe multiprofissional, violência contra a mulher, violência sexual. 